\title{
Synaptic Characteristics of Dentate Gyrus Axonal Boutons and Their Relationships with Aging, Menopause, and Memory in Female Rhesus Monkeys
}

\author{
Yuko Hara, ${ }^{1}$ C. Sehwan Park, ${ }^{1}$ William G. M. Janssen, ${ }^{1}$ Michael Punsoni, ${ }^{1}$ Peter R. Rapp, ${ }^{4}$ and John H. Morrison ${ }^{1,2,3}$ \\ ${ }^{1}$ Fishberg Department of Neuroscience and Kastor Neurobiology of Aging Laboratories, ${ }^{2}$ Department of Geriatrics and Palliative Medicine, and \\ ${ }^{3}$ Computational Neurobiology and Imaging Center, Mount Sinai School of Medicine, New York, New York 10029, and ${ }^{4}$ Laboratory of Experimental \\ Gerontology, National Institute on Aging, Baltimore, Maryland 21224
}

\begin{abstract}
Age-related memory impairment occurs in many mammalian species, including humans. Moreover, women undergoing the menopausal transition often complain of problems with memory. We recently reported that rhesus monkeys display age- and menopause-related recognition memory impairment on a hippocampus-reliant test [delayed nonmatching-to-sample (DNMS)]. In the same monkeys, perforated synapse densities in the dentate gyrus outer molecular layer (OML) correlated with DNMS recognition accuracy, while total axospinous synapse density was similar across age and menses groups. The current study examined whether synaptic characteristics of OML axonal boutons are coupled with age- or menopause-related memory deficits. Using serial section electron microscopy, we measured the frequencies of single-synapse boutons (SSBs), multiple-synapse boutons (MSBs), and boutons with no apparent synaptic contacts [nonsynaptic boutons (NSBs)] in the OML. Aged females had double the percentage of NSBs compared with young females, and this measure correlated positively and inversely with DNMS acquisition (number of trials to criterion) and delay performance (average accuracy), respectively. Aged compared with young females also had a lower frequency of MSBs and a lower number of synaptic contacts per MSB, and the latter variable inversely correlated with DNMS acquisition. Although proportions of NSBs, SSBs, and MSBs were similar across menses groups, compared with premenopausal monkeys, peri/postmenopausal monkeys had fewer MSBs contacting one or more segmented perforated synapses, and the abundance of this bouton subtype positively correlated with DNMS performance. These results suggest that age- and menopause-related shifts in OML synaptic subtypes may be coupled with deficits in task acquisition and recognition memory.
\end{abstract}

\section{Introduction}

Age-related memory loss has been attributed, in part, to structural alterations in the perforant path (Hyman et al., 1984; Flood et al., 1987; Cabalka et al., 1992; Morrison and Hof, 1997; Yassa et al., 2010), an excitatory projection from the entorhinal cortex to the dentate gyrus (DG) of the hippocampus (Witter et al., 1989; Lambert and Jones, 1990). Recognition memory, as measured in monkeys by the delayed nonmatching-to-sample (DNMS) task, requires the hippocampal formation and the perirhinal cortex (Mishkin, 1978; Squire and Zola-Morgan, 1991) and is vulnerable to age- and menopause-related decline (Presty et al., 1987; Moss et al., 1988; Rapp and Amaral, 1991; Hara et al., 2010). A

Received Feb. 14, 2011; revised April 12, 2011; accepted April 13, 2011.

Author contributions: Y.H., P.R.R., and J.H.M. designed research; Y.H., C.S.P., W.G.M.J., and M.P. performed research;Y.H. analyzed data; Y.H., P.R.R., and J.H.M. wrote the paper.

This work was supported by National Institute on Aging Grants R37 AG06647 and R01 AG010606 to J.H.M., and in part by the Intramural Research Program of the National Institute on Aging. This study was conducted while Y.H. was an Ellison Medical Foundation/AFAR Postdoctoral Fellow. We thank Mary Roberts, Sania Fong, Deborah Kent, Katie Hartley, Sona Santos, Heather McKay, Anne Canfield, Susan Fink, Ginelle Andrews, Shannon Wadsworth, and Rishi Puri for expert technical assistance, and Dr. Donald Canfield for assistance in veterinary work.

Correspondence should be addressed to Dr. John H. Morrison, Department of Neuroscience, Box 1065, Mount Sinai School of Medicine, One Gustave L. Levy Place, New York, NY 10029. E-mail: john.morrison@mssm.edu.

DOI:10.1523/JNEUROSCI.0822-11.2011

Copyright $\odot 2011$ the authors $\quad 0270-6474 / 11 / 317737-08 \$ 15.00 / 0$ magnetic resonance imaging study reported that within the hippocampus, the DG is particularly vulnerable to normal aging, and that energy metabolism in this region is correlated with DNMS memory scores (Small et al., 2004).

The DG volume, granule cell number, and synapse density remain stable in the aged monkey (Tigges et al., 1995, 1996; Peters et al., 1996; Hao et al., 2003; Keuker et al., 2003; Calhoun et al., 2004; Hara et al., 2010). Furthermore, the number of entorhinal cortex neurons that project to the DG does not change with age in the rhesus monkey (Rapp, 1995; Gazzaley et al., 1997; Merrill et al., 2000). Thus, the current study tested the possibility that recognition memory decline in aged monkeys is coupled with changes in the characteristics of DG outer molecular layer (OML) axonal boutons, which are terminals of the perforant path originating in layer II of the entorhinal cortex (Witter et al., 1989). Using serial section electron microscopy, we measured the frequencies of single-synapse boutons (SSBs), multiple-synapse boutons (MSBs), and boutons with no apparent synaptic contacts [nonsynaptic boutons (NSBs)] in the OML. MSBs are presynaptic boutons synaptically connected to more than one dendrite or dendritic spine. A potential function of MSBs is that they act as a morphological substrate to increase coupling between presynaptic and postsynaptic neurons (Harris, 1995; Toni 
et al., 1999; Geinisman et al., 2001; Yankova et al., 2001). MSBs are increased in the hippocampal CA1 after hippocampusdependent associative learning in rats (Geinisman et al., 2001). MSBs are also implicated in structural plasticity (Jones et al., 1999; Toni et al., 1999), and their frequency increases after induction of long-term potentiation (LTP), a phenomenon underlying synaptic plasticity (Toni et al., 2001). Interestingly, estradiol administration to ovariectomized female rats enhances the prevalence of MSBs in CA1 (Woolley et al., 1996). Thus, we sought to determine whether the proportions of MSBs are altered with aging or menopause. In contrast, NSBs are boutons that make no synaptic contacts. Even in the absence of postsynaptic targets, morphologically normal presynaptic boutons can form and release neurotransmitters (Henrikson and Vaughn, 1974; Prokop et al., 1996; Krueger et al., 2003). Our study is the first to highlight the changes in frequencies of NSBs with aging and memory decline.

\section{Materials and Methods}

Animals. Subjects comprised 5 young adult (age range, 9-11 years old; mean, 9.72 years old) and 13 aged (age range, 22-35 years old; mean, 29.13 years old) female rhesus monkeys (Macaca mulatta). The average life span of captive rhesus monkeys is $<25$ years and human age equivalence is estimated at 1:3 (Tigges et al., 1988). Menopause in rhesus monkeys occurs by 27 years old, which is later in life relative to humans (Gilardi et al., 1997; Walker and Herndon, 2008). None of the subjects participated in previous invasive or pharmacological studies expected to influence the cognitive or neurobiological measures examined here. Monkeys were housed in colonies of $\sim 40$ individuals at the California National Primate Research Center, University of California, Davis, and visual inspection for vaginal bleeding was conducted daily for 2 years before perfusion. Normal cycle length (interval between the first days of menses) in young adult rhesus macaques is $\sim 24-34 \mathrm{~d}$ (Gilardi et al., 1997), but because vaginal bleeding may have escaped detection in some cases, we adopted a more liberal cycle length criterion of 24-45 d (average cycle length in the last 12 months) to classify monkeys as eumenorrheic (regular menstruation). Average cycle lengths beyond these values were classified as oligomenorrheic (irregular menstruation), or amenorrheic (absence of menstruation), in cases where monkeys had $2 \mathrm{~d}$ or fewer of vaginal bleeding in the last 12 months of observation. Eumenorrheic monkeys were classified as premenopausal. The transition between periand postmenopausal status is difficult to determine with precision, and therefore, we adopted the convention of an earlier study (Gilardi et al., 1997), classifying oligomenorrheic and amenorrheic aged monkeys together as peri/postmenopausal. Ovarian status was confirmed by urinalysis of endocrine data for 11 of 18 monkeys. All experiments were conducted in compliance with the National Institutes of Health Guidelines for the Care and Use of Experimental Animals and approved by the Institutional Animal Care and Use Committee at the University of California, Davis.

Delayed nonmatching-to-sample test. DNMS testing was conducted in a manual apparatus as described previously (Rapp and Amaral, 1991; Rapp et al., 2003). Briefly, a sample object was placed over a food reward in the central well of the test tray, and after the subject retrieved the reward, an opaque barrier was lowered to impose the retention interval. The sample item was subsequently presented together with a novel object, and the subject was rewarded for choosing the novel object. Objects were drawn from a large pool such that new objects were presented on each trial. Throughout the trials, a one-way mirror hid the experimenter from view when monkeys responded, and a white-noise generator masked extraneous sounds. During the acquisition phase, monkeys learned the nonmatching rule of the task with a $10 \mathrm{~s}$ retention interval. Once monkeys reached a criterion of $90 \%$ correct or better at this delay interval (across 100 trials, 20 trials/d), recognition memory was challenged by imposing successively longer delays of $15,30,60,120 \mathrm{~s}(100$ trials total at each delay, 20 trials/d), and $600 \mathrm{~s}$ (50 trials total, 5 trials/d).
Intertrial interval was $30 \mathrm{~s}$ throughout testing. Monkeys remained in the test chamber during all retention intervals.

When perfusion could not be scheduled shortly after completion of behavioral testing, monkeys continued mock training until the day before perfusion to avoid testing-induced variability in morphological measures. There were no significant differences by age or menses groups in the amount of time lapsed between the last day of DNMS testing and the perfusion date $(p>0.05)$. Furthermore, no correlations were found between the amount of time lapsed and any of the behavioral and morphological measures examined ( $p>0.05)$.

Perfusion and tissue processing. Animals were deeply anesthetized with ketamine hydrochloride $(25 \mathrm{mg} / \mathrm{kg})$ and pentobarbital $(20-35 \mathrm{mg} / \mathrm{kg}$, i.v.), intubated, and mechanically ventilated. The chest was opened and $1.5 \mathrm{ml}$ of $0.5 \%$ sodium nitrate was injected into the left ventricle of the heart. After clamping the descending aorta, animals were perfused transcardially with cold $1 \%$ paraformaldehyde in $0.1 \mathrm{~m}$ phosphate buffer $(\mathrm{PB})$ ( $\mathrm{pH} 7.2$ ) for $2 \mathrm{~min}$, followed by $4 \%$ paraformaldehyde in $0.1 \mathrm{M} \mathrm{PB}$ at 250 $\mathrm{ml} / \mathrm{min}$ for $10 \mathrm{~min}$. Fixative flow rate was then reduced to $100 \mathrm{ml} / \mathrm{min}$ for $50 \mathrm{~min}$. Following perfusion, the brain was removed from the skull and dissected in such a way that the entire hippocampal region was included in a single block. The hippocampal block from the right side of the brain was postfixed for $6 \mathrm{~h}$ in $4 \%$ paraformaldehyde in $0.1 \mathrm{M} \mathrm{PB}$ with $0.125 \%$ glutaraldehyde, washed in $0.1 \mathrm{M} \mathrm{PB}$, and cut into $400-\mu \mathrm{m}-$ thick sections on a vibratome (Leica). Freeze substitution and lowtemperature embedding of the specimens were performed as previously described (Chaudhry et al., 1995). Briefly, slices were cryoprotected by immersion in increasing concentrations of glycerol $(10,20$, and $30 \%$ ) in $0.1 \mathrm{M} \mathrm{PB}$, and then plunged in liquid propane cooled by liquid nitrogen $\left(-190^{\circ} \mathrm{C}\right)$ in a Universal Cryofixation System KF80 (ReichertJung). Samples were immersed in $1.5 \%$ uranyl acetate in anhydrous methanol $\left(-90^{\circ} \mathrm{C}\right)$ for $24 \mathrm{~h}$ in a cryosubstitution Automatic FreezeSubstitution System unit (Leica). The temperature was raised in steps of $4^{\circ} \mathrm{C} / \mathrm{h}$ from -90 to $-45^{\circ} \mathrm{C}$. The samples were washed with anhydrous methanol and infiltrated with Lowicryl HM20 resin (Electron Microscopy Sciences) at $-45^{\circ} \mathrm{C}$, with a progressive increase in the ratio of resin to methanol for $1 \mathrm{~h}$ each, followed by pure Lowicryl overnight. Polymerization of the resin was performed with UV light $(360 \mathrm{~nm})$ at $-45^{\circ} \mathrm{C}$ for $48 \mathrm{~h}$, followed by $24 \mathrm{~h}$ at room temperature. Fifteen or more consecutive ultrathin sections were cut into 90 -nm-thick sections using a Diatome diamond knife (Electron Microscopy Sciences) and mounted on each Formvar-supported slot grid (Electron Microscopy Sciences). The thickness was later confirmed to be accurate, using Small's technique (Small, $1968)$ of minimal folds $(88.9 \pm 2.2 \mathrm{~nm})$. To ensure that images were taken from the OML, the thickness of the entire DG molecular layer was measured. Images were taken only from areas well within the outer twothirds of the molecular layer thickness, where perforant path inputs from the entorhinal cortex terminate (Witter et al., 1989). Fields containing cell bodies and blood vessels were excluded. The electron micrographs were adjusted for brightness and sharpness with Adobe Photoshop (version CS5, Adobe Systems Inc.), and then imported into PowerPoint (Microsoft Office 2003) to make composite plates. Three-dimensional reconstructions of a subset of perforated synapses were performed using free software developed by Dr. Kristen Harris and her laboratory (Reconstruct, version 1.1.0.0; http://synapses.clm.utexas.edu).

Quantitative analyses of synaptic bouton characteristics. For each monkey in the study, 5 series of 15 consecutive ultrathin sections were imaged at $12,000 \times$ on a Hitachi H-7000 electron microscope using an AMT Advantage CCD camera (Advanced Microscopy Techniques). The total volume examined per monkey was $843.3 \mu \mathrm{m}^{3}$. For each series, the middle section (eighth section) was used as a reference section (Fig. 1). All presynaptic boutons containing at least 3 synaptic vesicles that were transected in this middle section were identified. Approximately 200 boutons were identified and analyzed per monkey. Each bouton was followed throughout the series, and all synaptic contacts were marked. The following measures were examined: (1) percentage of MSBs, SSBs, and NSBs; (2) the average number of synaptic contacts formed per MSB; and (3) the types of synapses (axospinous vs axodendritic and nonperforated vs perforated) formed by each bouton. Perforated synaptic contacts were further categorized into three subtypes: fenestrated, horseshoe-shaped, and 

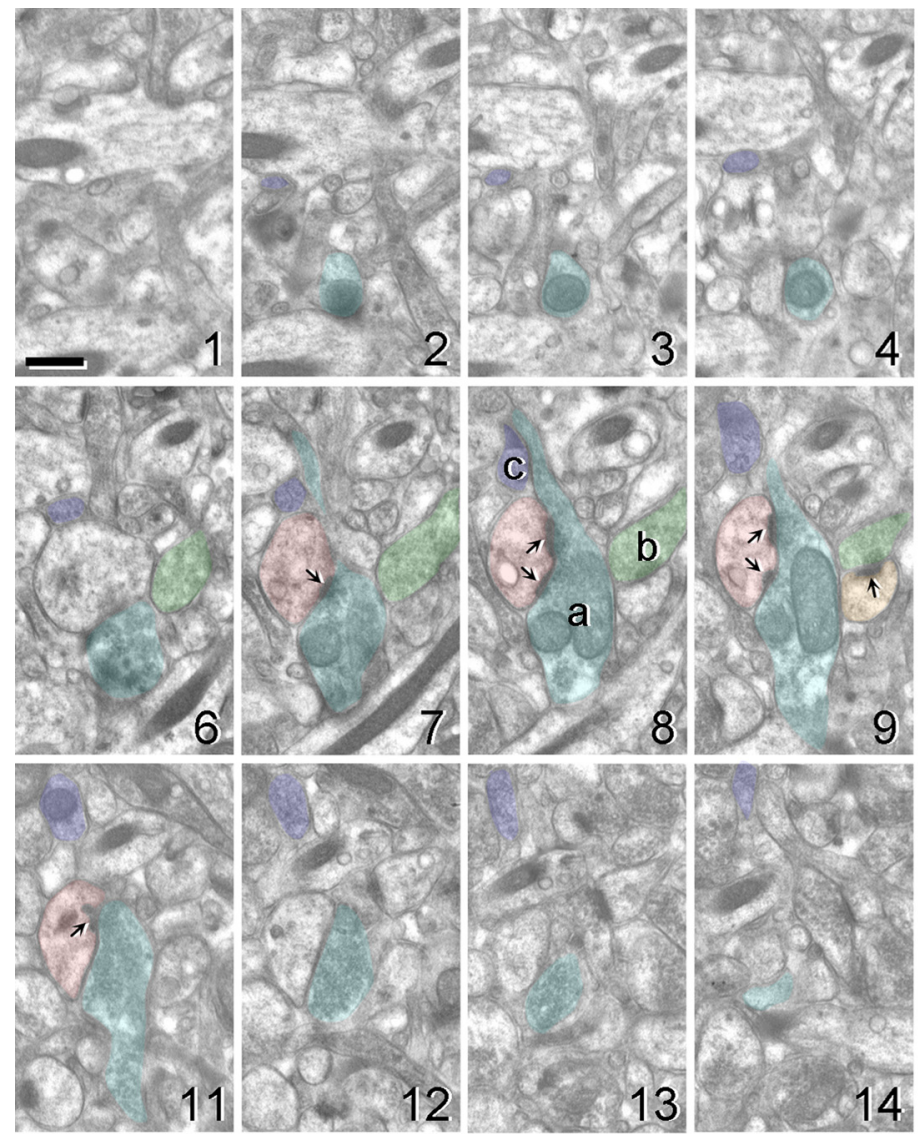

Figure 1. Electron micrographs of 15 serial ultrathin sections illustrating the methods involved in obtaining axonal bouton measures. The middle section (eighth section) was used as a reference section. All presynaptic boutons containing at least 3 synaptic vesicles that were transected in this middle section were identified (boutons a-c). Each bouton was then followed throughout the series, and all excitatory asymmetric synaptic contacts were marked. Asymmetric synaptic contacts contained a thick postsynaptic density (arrows). In this example, bouton a (blue) forms a synaptic contact with a single segmented perforated synapse (pink, sections 7-11), bouton b (green) forms a multiple-synaptic contact with two spines (orange, sections 9/10; and yellow, section 5), and bouton c (purple) does not form any synaptic contacts. Scale bar, $500 \mathrm{~nm}$.

segmented (Geinisman et al., 1987, 1992). After planar reconstruction, a postsynaptic density (PSD) with a hole(s) was classified as a fenestrated perforated synapse, while a U-shaped PSD was classified as a horseshoe perforated synapse. A segmented perforated synapse had two or more separate PSD plates. Boutons that made inhibitory-type symmetric synapses were excluded from the analyses. Volumes of 50 randomly chosen boutons per monkey were estimated by determining the cross-sectional areas of the boutons using the Adobe Photoshop lasso tool in each section and multiplying the total area with the section thickness.

Statistical analyses. Statistical analyses were performed using SPSS 11.0. The behavioral and morphological data were not significantly different from a normal distribution ( $p>0.05$, one-sample KolmogorovSmirnov test), and accordingly, parametric statistics were used to test for potential differences across groups. ANOVA was used to determine whether behavioral or morphological measures differed by age (young vs aged). ANOVA followed by Fisher's post hoc test was used for comparisons between groups designated by age and menses status (young premenopausal, aged premenopausal, and aged peri/postmenopausal). To evaluate potential effects of menses status on synaptic morphology while controlling for the influence of chronological age, the data were further explored by ANCOVA with chronological age as the covariate. To determine whether the frequencies of different-sized axon boutons, as measured by bouton volume, differed between groups, the cumulative frequency distribution of bouton volume was compared using the Kruskal-Wallis test. ANOVA was used to determine whether bouton volumes differed by bouton subtype. Pearson correlations evaluated the relationships between OML morphological indices and DNMS measures
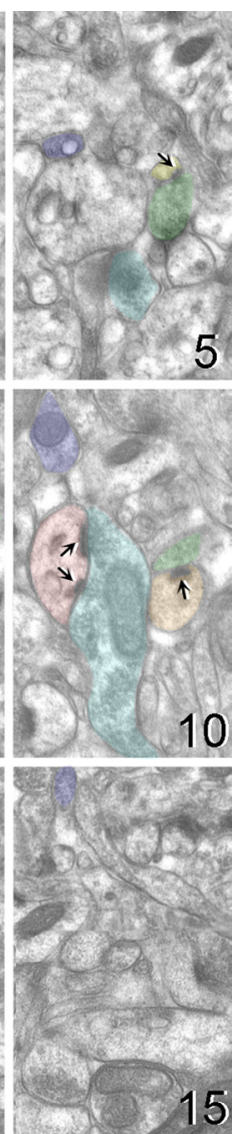

(acquisition and delay performance). The $\alpha$ level was set at 0.05 for statistical significance. Observed power calculations in ANOVA were used to confirm that the sample size was sufficient to support the data.

\section{Results}

\section{Behavioral characterization}

Behavioral data for the majority of monkeys included in the present analysis (14 of 18) have been presented in detail previously (Hara et al., 2010), and considered together with data from four additional monkeys in this study, the overall pattern remains similar to many previous reports (Rapp et al., 2003; Shamy et al., 2006; Dumitriu et al., 2010). Briefly, aged female monkeys $(n=13$; mean \pm SEM, $770.15 \pm 120.23)$ required significantly more trials than young female adults $(n=$ $5 ; 136.60 \pm 34.32)$ to acquire the DNMS task initially with a $10 \mathrm{~s}$ delay (one-way ANOVA, main age effect; $F_{(1,16)}=10.18$; $p=0.006$, observed power $=0.849$ ). When memory was subsequently challenged with successively longer delays (15-600 s), repeated-measures ANOVA revealed main effects of age (main age effect; $F_{(1,16)}=22.27, p=0.0002$, observed power $=0.993$; Fig. 2 ), and delay (delay effect; $F_{(4,64)}=44.49 ; p<0.00001$; observed power $=1.000)$, but no age by delay interaction $(p>0.05)$.

We have previously shown that menses status has a significant effect on DNMS delay performance after accounting for chronological age (Hara et al., 2010). In this cohort, aged premenopausal females also scored higher than aged peri/postmenopausal monkeys at all delay intervals longer than $15 \mathrm{~s}$, but this trend was not statistically significant $(p>0.05$, data not shown).

\section{Lack of age- or menses-related differences in density and size of DG OML axonal boutons}

One-way ANOVA showed a lack of age or menses effects on the total number of boutons observed per unit area $(p>0.05$; young premenopausal, $200.4 \pm 4.3$; aged premenopausal, $202.2 \pm 4.3$; aged peri/postmenopausal, $194.1 \pm 3.4)$. In all monkeys examined, regardless of age or menses status, only $11-16 \%$ of OML boutons extended beyond the 15 serial sections used in the analyses (young premenopausal, $12.0 \pm 2.9 \%$; aged premenopausal, $15.7 \pm 2.9 \%$; aged peri/postmenopausal, $11.0 \pm 2.4 \%$ ). Because the proportions of boutons extending beyond the 15 sections were similar across groups, all boutons were included in the analyses so as not to preferentially exclude large boutons. No differences in average bouton volumes were found among age/menses groups ( $p>0.05$; mean \pm SEM: young premenopausal, $0.142 \pm$ $0.013 \mu \mathrm{m}^{3}$; aged premenopausal, $0.146 \pm 0.022 \mu \mathrm{m}^{3}$; aged peri/ postmenopausal, $\left.0.144 \pm 0.009 \mu \mathrm{m}^{3}\right)$. We also tested for potential age- or menses status-dependent shift in the frequency of different-sized boutons. Results of a Kruskal-Wallis test indicated that the cumulative frequency distributions of bouton vol- 


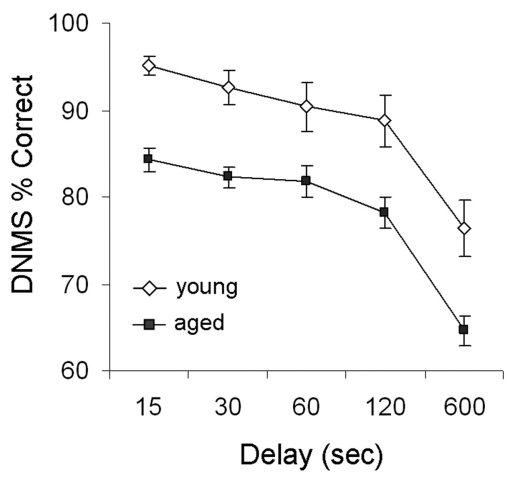

Figure 2. Performance on the delay portion of the DNMS test by age. Aged female monkeys exhibited significantly lower accuracy across all retention intervals $(15,30,60,120$, and $600 \mathrm{~s})$ compared with the young. Group results are expressed as mean \pm SEM; young females, $n=5$; aged females, $n=13$.

umes were equivalent across young premenopausal, aged premenopausal, and aged peri/postmenopausal groups $(p>$ $0.05)$, suggesting that the relative proportions of small and large boutons were similar across age and menses status.

While there were no effects of age or menses status, two-way ANOVA showed significant effects of bouton subtype (NSB, SSB, and MSB: $F_{(2,1784)}=15.078 ; p=3.99 \times 10^{-7}$; observed power $=$ 0.999 ) and PSD configuration (macular vs perforated: $F_{(1,893)}=$ $44.240 ; p=5.28 \times 10^{-26}$; observed power $\left.=1.000\right)$ on bouton volumes. Fisher's post hoc test revealed that MSBs $(0.209 \pm 0.010$ $\left.\mu \mathrm{m}^{3}\right)$ were significantly larger than SSBs $\left(0.120 \pm 0.005 \mu \mathrm{m}^{3}\right.$; $\left.p=5.10 \times 10^{-9}\right)$ and NSBs $\left(0.085 \pm 0.008 \mu \mathrm{m}^{3} ; p=6.48 \times\right.$ $\left.10^{-9}\right)$. SSBs were larger than NSBs but did not achieve statistical significance $(p=0.070)$. Axonal boutons rarely contacted more than one perforated synapse. Boutons contacting one or more perforated synapses regardless of subtype $\left(0.272 \pm 0.019 \mu \mathrm{m}^{3}\right)$ were significantly larger than those contacting only nonperforated (macular) synapses $\left(0.144 \pm 0.006 \mu \mathrm{m}^{3}\right)$.

\section{Differences in synaptic characteristics of DG OML axonal boutons by age and menses status}

We next examined whether proportions of axonal bouton subtypes differ by age or menses status. One-way ANOVA revealed a significant age effect on the proportions of $\operatorname{NSBs}\left(F_{(1,16)}=\right.$ 13.937, $p=0.002$, observed power $=0.938)$ such that aged females $(10.37 \pm 0.68 \%)$ had approximately twice the percentage of NSBs compared with young females (5.78 $\pm 0.87 \%$; Fig. $3 A)$. A significant age effect was also observed in the frequency of MSBs $\left(F_{(1,16)}=4.780, p=0.044\right.$, observed power $\left.=0.538\right)$ such that aged compared with young females had a lower frequency of MSBs (Fig. 3A). In addition, young (2.41 \pm 0.03$)$ compared with aged $(2.33 \pm 0.02)$ females had a higher number of synaptic contacts per MSB (age effect: $F_{(1,16)}=4.588, p=0.048$, observed power $=0.521)$. There were no differences between young and aged females in the proportions of SSBs or boutons contacting dendritic shafts, whether single- or multiple-synaptic $(p>0.05)$.

When the influence of age was accounted for, no differences were seen in the proportions of NSBs, SSBs, or MSBs as a function of menses status (ANCOVA, $p>0.05$; Fig. 3B). However, oneway ANOVA revealed main group effects in the proportions of MSBs contacting one (or more) fenestrated perforated synapse $\left(F_{(2,30)}=4.062 ; p=0.039\right.$; observed power $\left.=0.630\right)$ and one $($ or more $)$ segmented perforated synapse $\left(F_{(2,30)}=4.430 ; p=0.031\right.$; observed power $=0.670$; Fig. 4 ). Fisher's post hoc tests showed
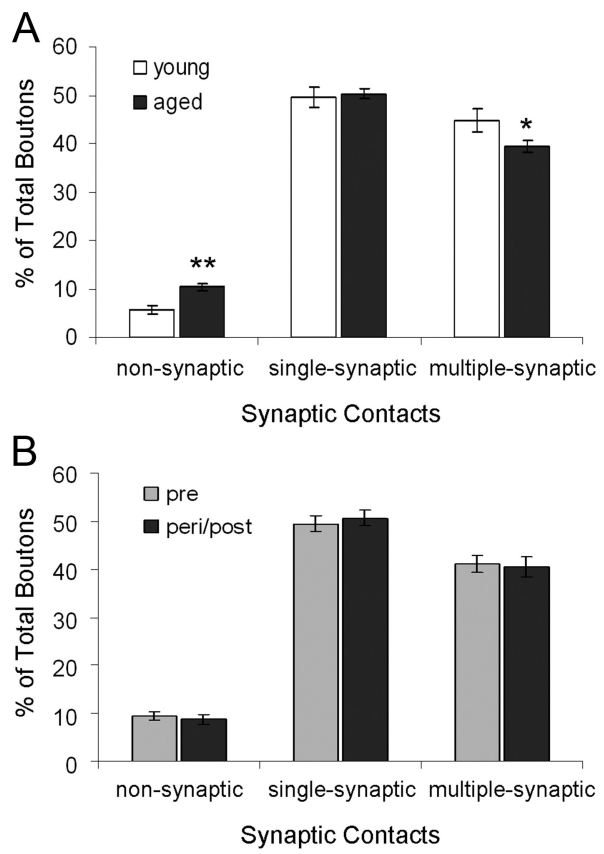

Figure 3. Synaptic characteristics of DG OML axonal boutons by age and menses status. $\boldsymbol{A}$ The proportions of nonsynaptic, single-synaptic, and multiple-synaptic boutons are plotted by age and expressed as mean \pm SEM. $\boldsymbol{B}$, The proportions of nonsynaptic, single-synaptic, and multiple-synaptic boutons are plotted by menses status and expressed as covariate (age)adjusted mean \pm SE. ${ }^{*} p<0.05,{ }^{* *} p<0.01$; young females, $n=5$; aged females, $n=13$; premenopausal, $n=10$; peri/postmenopausal, $n=8$.

that aged premenopausal monkeys had more MSBs contacting one (or more) fenestrated perforated synapse than aged peri/ postmenopausal monkeys $(p=0.014)$ and young premenopausal monkeys, but the comparison with young premenopausal monkeys did not reach statistical significance ( $p=0.053$; Fig. 4$)$. Fisher's post hoc tests also revealed that aged peri/postmenopausal monkeys exhibited a lower proportion of MSBs contacting one (or more) segmented perforated synapse than both young $(p=0.023)$ and aged $(p=0.029)$ premenopausal monkeys (Fig. $4)$. No differences across groups were found in the proportions of MSBs contacting a horseshoe perforated synapse (Fig. 4) or SSBs contacting any of the three subtypes of perforated synapses $(p>$ $0.05)$. There were no differences between groups in the proportions of boutons contacting dendritic shafts, whether singlesynaptic or multiple-synaptic $(p>0.05)$.

\section{Relationships between DG OML axonal bouton subtypes and recognition memory}

Potential relationships between synaptic characteristics of DG OML axonal boutons and recognition memory were examined by a bivariate correlation approach. We first examined the relationship between DNMS acquisition (number of trials to reach the criterion of $90 \%$ correct or better with a 10 s delay) and OML synaptic measures. A significant positive correlation emerged between the percentage of NSBs and DNMS acquisition (Pearson correlation; $n=18, r=0.522, p=0.026$; Fig. $5 A$ ). Additionally, a significant inverse correlation was observed between the average number of synapses formed by MSBs and DNMS acquisition (Pearson correlation; $n=18, r=-0.551, p=0.018$; Fig. $5 B$ ). None of the other synaptic measures correlated with DNMS acquisition $(p>0.05)$.

We then examined possible relationships between OML synaptic measures and recognition memory scores, averaged across 

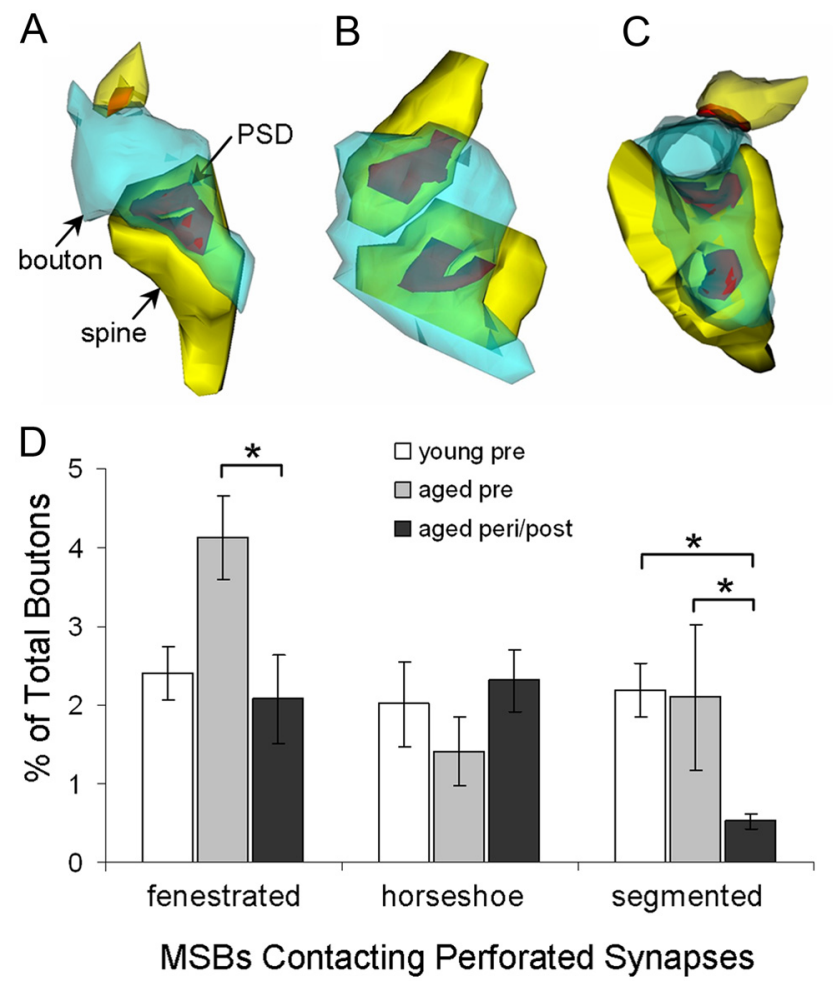

Figure 4. Types and proportions of perforated synapse-contacting MSBs by group. MSBs rarely contacted more than one perforated synapse. $\boldsymbol{A}-\boldsymbol{C}$, Most perforated synapse-contacting MSBs contacted one fenestrated $(\boldsymbol{A})$, horseshoe-shaped $(\boldsymbol{B})$, or segmented $(\boldsymbol{C})$ perforated synapse and one (or more) nonperforated synapse. Dendritic spine, yellow; axonal bouton, blue; PSD, red. $\boldsymbol{D}$, The proportions of MSBs contacting one or more fenestrated, horseshoe-shaped, and segmented perforated synapses are expressed as mean \pm SEM. ${ }^{*} p<0.05$; young premenopausal, $n=5$; aged premenopausal, $n=5$; aged peri/postmenopausal, $n=8$.

all retention intervals $(15-600 \mathrm{~s})$. This analysis revealed a significant inverse correlation between the percentage of NSBs and DNMS delay performance (Fig. $6 \mathrm{~A}$; Pearson correlation; $n=18$, $r=-0.600, p=0.008)$. There was also a significant positive correlation between the frequency of MSBs contacting one or more segmented perforated synapses and DNMS performance (Fig. 6 B; Pearson correlation; $n=18, r=0.494, p=0.037$ ). None of the other synaptic measures correlated with DNMS delay performance $(p>0.05)$.

\section{Discussion}

In contrast to previously reported postsynaptic changes observed in relation to menopause (Hara et al., 2010), the present study revealed striking age-dependent differences in the synaptic characteristics of DG OML axonal boutons. While the density and size of axonal boutons within the DG OML were similar across age, aged monkeys exhibited double the proportion of NSBs and a lower proportion of MSBs compared with young monkeys. Most notably, the proportion of NSBs correlated with both acquisition and delay accuracy on DNMS. Our findings point to perforant path NSBs as a novel and important target of aging and memory and suggest that the increase in NSBs with aging may be a deterrent to both task acquisition and memory performance. In addition, the number of synaptic contacts per MSB was lower in aged compared with young animals, and this measure also correlated with DNMS acquisition. Together, these findings suggest that while NSBs interfere with learning, MSBs in the OML may facilitate acquisition of novel tasks.
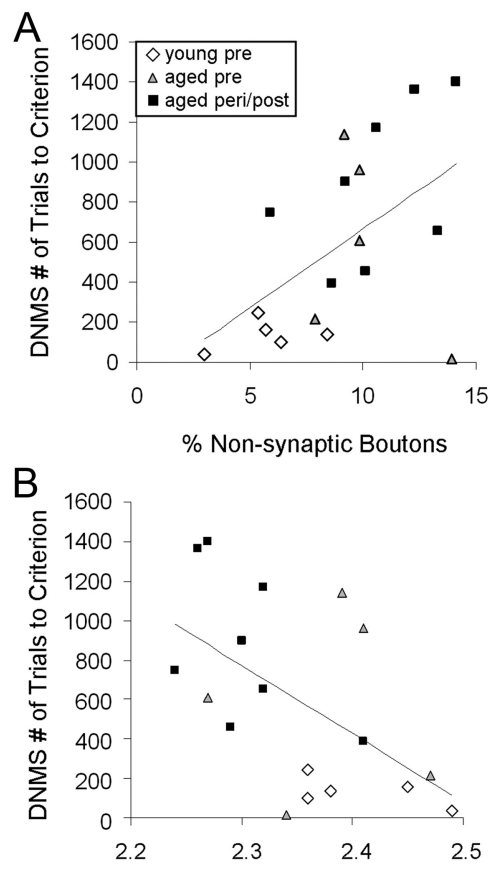

Average \# of Synapses Made by MSBs

Figure 5. Morphological measures for individual subjects in the DG OML in relation to DNMS acquisition. $\boldsymbol{A}$, A significant positive correlation is seen between the percentage of NSBs and DNMS acquisition (number of trials to reach criterion). $\boldsymbol{B}, A$ significant inverse correlation is observed between the average number of synapses formed by MSBs and DNMS acquisition. $n=18$.
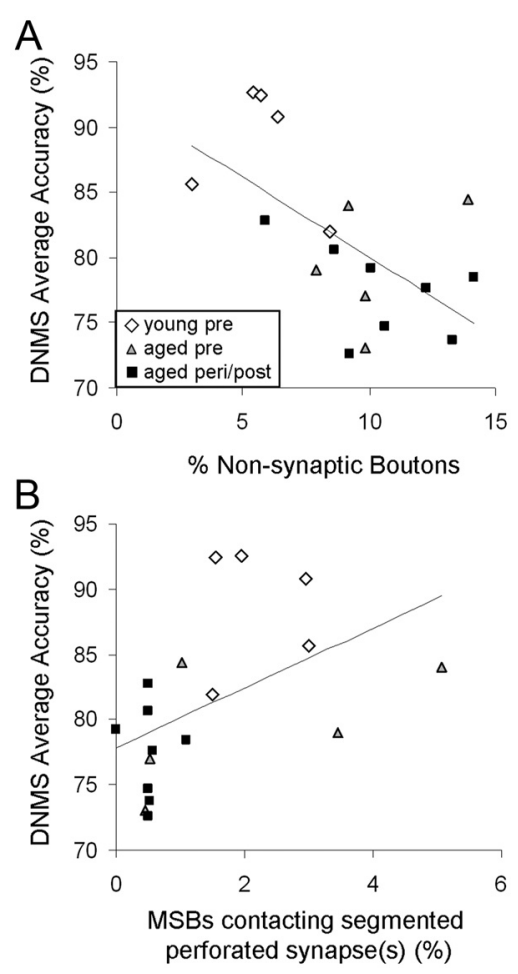

Figure 6. The proportions of bouton subtypes in the DG OML in relation to DNMS delay performance. $A, A$ significant inverse correlation is observed between the percentage of NSBs and DNMS average accuracy (across all delay intervals). $\boldsymbol{B}$, A significant positive correlation is seen between DNMS average accuracy and the percentage of boutons that are multiplesynaptic and contacting one or more segmented perforated synapses. $n=18$. 


\section{Methodological considerations}

Rhesus monkeys provide an attractive model for studying the basis of cognitive aging, because they develop age-related hippocampal dysfunction (Presty et al., 1987; Moss et al., 1988) and undergo menopause similar to humans (Gilardi et al., 1997; Walker and Herndon, 2008). In addition, they do not develop the neurodegenerative characteristics of Alzheimer's disease (Peters et al., 1999; Kimura et al., 2003). Thus, differences observed between young and aged groups can be generally attributed to aging in the absence of frank degeneration.

One limitation of electron microscopic methods is that micrographs are snapshots of synaptic structures that are highly dynamic. For example, NSBs observed in micrographs are unlikely to be constitutively nonsynaptic (Gogolla et al., 2007), but instead, reflect boutons in transition into, or retraction from, functional connections. Current technology does not allow for liveimaging of synaptic structures at a high resolution as can be obtained with electron microscopy. Serial section electron microscopy is the only method available for investigating synaptic subtypes such as those examined here, but inevitably our outputs reflect frequencies of subtypes at one given time point.

\section{Age-related changes in synaptic characteristics of DG OML axonal boutons}

One of our key findings was that aged compared with young females had a higher frequency of NSBs and a lower frequency of MSBs in the DG OML. Although our previous study showed an absence of a statistically significant age effect on axospinous synapse density in the DG OML, aged monkeys had synapse densities that were on average $10 \%$ lower than those in young monkeys (Hara et al., 2010). This difference can be accounted for by our current study showing an $\sim 5 \%$ increase in NSBs and an $\sim 5 \%$ decrease in MSBs in aged monkeys when considered as a percentage of total synapses. It is more likely that with age, some SSBs become NSBs, and MSBs turn into SSBs (Fig. 7), rather than MSBs losing all of their synaptic partners and transforming into NSBs. Regardless, these shifts in synaptic subtypes would result in a net decrease of synapse density in aged monkeys by $\sim 10 \%$. Thus, our current study was able to tease apart the two classes of synaptic connections (NSBs and MSBs) that are vulnerable to the effects of normal aging by using a more sensitive classification of synaptic subtypes.

The age-related difference in the frequency of NSBs was striking in that aged subjects had approximately twice the percentage compared with the young. This shift is likely to be a reflection of changes in the turnover of synapses. Aged compared with young female monkeys may have a slower rate of dendrites/spines reaching target boutons or a higher rate of spine retraction. Aged individuals may also have a lower rate of spine formation, as has been reported in the rat cortex (Yang et al., 2009). It is also conceivable that aged subjects have alterations in cell adhesion molecules (i.e., neuroligins, neurexins) that stabilize synapses (Majdi et al., 2009). Any of these hypothetical possibilities would result in a higher frequency of boutons that make no synaptic contact in aged monkeys.

Young female monkeys had a higher proportion of MSBs and a higher number of synaptic contacts per MSB compared with aged individuals. These results suggest that aged monkeys lose the synaptic subtype implicated in associative learning (Geinisman et al., 2001). In rat CA1, a great majority of MSBs form synapses with spines of multiple postsynaptic neurons rather than with spines within the same neurons (Yankova et al., 2001). If this pattern of synaptic connectivity also exists in monkey DG MSBs, then aged monkeys may have a decreased level of complexity in their neuronal circuit compared with young monkeys.

No differences in the axonal bouton density, average bouton volume, or size distributions were observed across age or menses groups, consistent with previous reports that axon terminal cross-sectional areas and synaptophysin protein levels in the OML are unaltered with age in rhesus monkeys (Tigges et al., 1995; Gazzaley et al., 1996). Our results are also in line with findings that rates of presynaptic terminal remodeling are slower relative to those of postsynaptic spines (Majewska et al., 2006), and many axonal boutons persist for months, if not for a lifetime (De Paola et al., 2006). We did find, however, that regardless of age or menses status, MSBs were larger than SSBs and NSBs and that boutons contacting one or more perforated synapses were larger than those contacting only macular synapses. These findings are similar to those of a study in the rat CA1 that demonstrated that MSBs are larger and more irregular in shape than SSBs (Woolley et al., 1996).

\section{Relationships between DG OML axonal bouton subtypes and recognition memory}

The percentage of OML NSBs positively and inversely correlated with DNMS acquisition and performance, respectively. Together, they suggest that perforant path NSBs may interfere with 
both the task acquisition and memory performance in DNMS. Our results are in line with a study showing that the extent of perforant path degradation in aged humans correlates with performance on a word-list learning task (Yassa et al., 2010). In an independent study using some of the same monkeys examined in this current report, total synapse density and average head volume of thin spines in area 46 of the prefrontal cortex showed significant correlations with DNMS acquisition (Dumitriu et al., 2010). While the critical synaptic subtypes are different, both area 46 and DG may be importantly engaged during acquisition of novel task rules.

We also discovered that the average number of synaptic contacts per MSB inversely correlates with DNMS acquisition, suggesting that boutons with many synaptic contacts may facilitate learning the DNMS task. With our current methods, we were unable to differentiate MSBs contacting same-neuron spines/ dendrites from those contacting different-neuron spines/dendrites. However, the study in rat CA1 showing a high frequency of MSBs forming synapses with multiple postsynaptic neurons (Yankova et al., 2001) suggests that DNMS acquisition may be facilitated with coincident depolarization of multiple neurons.

\section{Menses-related differences in synaptic characteristics of DG OML axonal boutons}

Our findings suggest that chronological and reproductive aging in female monkeys have independent consequences on synaptic morphology. Normal aging results in increased NSBs and decreased MSBs, while menopause does not appear to exacerbate these effects. Instead, compared with aged premenopausal monkeys, peri/postmenopausal monkeys exhibited a lower proportion of MSBs contacting one or more segmented perforated synapses (Fig. 7), and this measure correlated with DNMS delay performance. These results are consistent with our previous report showing reductions in perforated synapses with menopause and cognitive decline (Hara et al., 2010). In this current report, we identify a specific subtype of perforated synapse (segmented) and a specific class of synaptic connection (MSBs) as vulnerable to the effects of menopause and coupled with memory scores. Perforated synapses have been proposed to be a structural correlate of enhanced synaptic efficacy (Peters and KaisermanAbramof, 1969; Greenough et al., 1978; Geinisman et al., 1991). Aged rats with impaired hippocampus-dependent spatial memory show a decreased number of perforated synapses, and the loss of these perforated synapses correlates with the degree of spatial memory impairment (Geinisman et al., 1986a,b). The segmented subtype is especially interesting because of its selective increase after LTP induction (Geinisman et al., 1992, 1993). Furthermore, segmented perforated synapses are particularly rich in glutamate AMPA receptors (Ganeshina et al., 2004), which are major determinants of synaptic strength (Heynen et al., 2000; Kessels and Malinow, 2009). The present studies were conducted as part of a larger, integrated effort aimed at identifying the bases of age- and menopause-related cognitive impairment across multiple levels of analysis, from molecular to neural systems approaches. Future studies will investigate molecular targets in these synaptic subtypes including glutamate receptor subunits, which also likely contribute to cognitive function. Nevertheless, MSBs contacting one or more segmented perforated synapse may represent a bouton subtype that possesses the strongest synaptic strength and the ability to simultaneously depolarize multiple postsynaptic neurons. Despite the increase in NSBs with age, continued menstrual cycles or hormone replacement therapies may preserve this specific bouton subtype that maintains memory.

\section{References}

Cabalka LM, Hyman BT, Goodlett CR, Ritchie TC, Van Hoesen GW (1992) Alteration in the pattern of nerve terminal protein immunoreactivity in the perforant pathway in Alzheimer's disease and in rats after entorhinal lesions. Neurobiol Aging 13:283-291.

Calhoun ME, Mao Y, Roberts JA, Rapp PR (2004) Reduction in hippocampal cholinergic innervation is unrelated to recognition memory impairment in aged rhesus monkeys. J Comp Neurol 475:238-246.

Chaudhry FA, Lehre KP, van Lookeren Campagne M, Ottersen OP, Danbolt NC, Storm-Mathisen J (1995) Glutamate transporters in glial plasma membranes: highly differentiated localizations revealed by quantitative ultrastructural immunocytochemistry. Neuron 15:711-720.

De Paola V, Holtmaat A, Knott G, Song S, Wilbrecht L, Caroni P, Svoboda K (2006) Cell type-specific structural plasticity of axonal branches and boutons in the adult neocortex. Neuron 49:861-875.

Dumitriu D, Hao J, Hara Y, Kaufmann J, Janssen WG, Lou W, Rapp PR, Morrison JH (2010) Selective changes in thin spine density and morphology in monkey prefrontal cortex correlate with aging-related cognitive impairment. J Neurosci 30:7507-7515.

Flood DG, Buell SJ, Horwitz GJ, Coleman PD (1987) Dendritic extent in human dentate gyrus granule cells in normal aging and senile dementia. Brain Res 402:205-216.

Ganeshina O, Berry RW, Petralia RS, Nicholson DA, Geinisman Y (2004) Synapses with a segmented, completely partitioned postsynaptic density express more AMPA receptors than other axospinous synaptic junctions. Neuroscience 125:615-623.

Gazzaley AH, Siegel SJ, Kordower JH, Mufson EJ, Morrison JH (1996) Circuit-specific alterations of $N$-methyl-D-aspartate receptor subunit 1 in the dentate gyrus of aged monkeys. Proc Natl Acad Sci USA 93:3121-3125.

Gazzaley AH, Thakker MM, Hof PR, Morrison JH (1997) Preserved number of entorhinal cortex layer II neurons in aged macaque monkeys. Neurobiol Aging 18:549-553.

Geinisman Y, de Toledo-Morrell L, Morrell F (1986a) Loss of perforated synapses in the dentate gyrus: morphological substrate of memory deficit in aged rats. Proc Natl Acad Sci U S A 83:3027-3031.

Geinisman Y, de Toledo-Morrell L, Morrell F (1986b) Aged rats need a preserved complement of perforated axospinous synapses per hippocampal neuron to maintain good spatial memory. Brain Res 398:266-275.

Geinisman Y, Morrell F, de Toledo-Morrell L (1987) Axospinous synapses with segmented postsynaptic densities: a morphologically distinct synaptic subtype contributing to the number of profiles of 'perforated' synapses visualized in random sections. Brain Res 423:179-188.

Geinisman Y, deToledo-Morrell L, Morrell F (1991) Induction of long-term potentiation is associated with an increase in the number of axospinous synapses with segmented postsynaptic densities. Brain Res 566:77-88.

Geinisman Y, deToledo-Morrell L, Morrell F, Persina IS, Rossi M (1992) Structural synaptic plasticity associated with the induction of long-term potentiation is preserved in the dentate gyrus of aged rats. Hippocampus 2:445-456.

Geinisman Y, deToledo-Morrell L, Morrell F, Heller RE, Rossi M, Parshall RF (1993) Structural synaptic correlate of long-term potentiation: formation of axospinous synapses with multiple, completely partitioned transmission zones. Hippocampus 3:435-445.

Geinisman Y, Berry RW, Disterhoft JF, Power JM, Van der Zee EA (2001) Associative learning elicits the formation of multiple-synapse boutons. J Neurosci 21:5568-5573.

Gilardi KV, Shideler SE, Valverde CR, Roberts JA, Lasley BL (1997) Characterization of the onset of menopause in the rhesus macaque. Biol Reprod 57:335-340.

Gogolla N, Galimberti I, Caroni P (2007) Structural plasticity of axon terminals in the adult. Curr Opin Neurobiol 17:516-524.

Greenough WT, West RW, DeVoogd TJ (1978) Subsynaptic plate perforations: changes with age and experience in the rat. Science 202:1096-1098.

Hao J, Janssen WG, Tang Y, Roberts JA, McKay H, Lasley B, Allen PB, Greengard P, Rapp PR, Kordower JH, Hof PR, Morrison JH (2003) Estrogen increases the number of spinophilin-immunoreactive spines in the hippocampus of young and aged female rhesus monkeys. J Comp Neurol 465:540-550.

Hara Y, Park CS, Janssen WGM, Roberts MT, Morrison JH, Rapp PR (2010) Synaptic correlates of memory and menopause in the hippocampal den- 
tate gyrus in rhesus monkeys. Neurobiol Aging. Advance online publication. Retrieved October 26, 2010. doi:10.1016/j.neurobiolaging.2010.09.014.

Harris KM (1995) How multiple-synapse boutons could preserve input specificity during an interneuronal spread of LTP. Trends Neurosci 18:365-369.

Henrikson CK, Vaughn JE (1974) Fine structural relationships between neurites and radial glial processes in developing mouse spinal cord. J Neurocytol 3:659-675.

Heynen AJ, Quinlan EM, Bae DC, Bear MF (2000) Bidirectional, activitydependent regulation of glutamate receptors in the adult hippocampus in vivo. Neuron 28:527-536.

Hyman BT, Van Hoesen GW, Damasio AR, Barnes CL (1984) Alzheimer's disease: cell-specific pathology isolates the hippocampal formation. Science 225:1168-1170.

Jones TA, Chu CJ, Grande LA, Gregory AD (1999) Motor skills training enhances lesion-induced structural plasticity in the motor cortex of adult rats. J Neurosci 19:10153-10163.

Kessels HW, Malinow R (2009) Synaptic AMPA receptor plasticity and behavior. Neuron 61:340-350.

Keuker JI, Luiten PG, Fuchs E (2003) Preservation of hippocampal neuron numbers in aged rhesus monkeys. Neurobiol Aging 24:157-165.

Kimura N, Tanemura K, Nakamura S, Takashima A, Ono F, Sakakibara I, Ishii Y, Kyuwa S, Yoshikawa Y (2003) Age-related changes of Alzheimer's disease-associated proteins in cynomolgus monkey brains. Biochem Biophys Res Commun 310:303-311.

Krueger SR, Kolar A, Fitzsimonds RM (2003) The presynaptic release apparatus is functional in the absence of dendritic contact and highly mobile within isolated axons. Neuron 40:945-957.

Lambert JD, Jones RS (1990) A reevaluation of excitatory amino acidmediated synaptic transmission in rat dentate gyrus. J Neurophysiol 64:119-132.

Majdi M, Ribeiro-da-Silva A, Cuello AC (2009) Variations in excitatory and inhibitory postsynaptic protein content in rat cerebral cortex with respect to aging and cognitive status. Neuroscience 159:896-907.

Majewska AK, Newton JR, Sur M (2006) Remodeling of synaptic structure in sensory cortical areas in vivo. J Neurosci 26:3021-3029.

Merrill DA, Roberts JA, Tuszynski MH (2000) Conservation of neuron number and size in entorhinal cortex layers II, III, and V/VI of aged primates. J Comp Neurol 422:396-401.

Mishkin M (1978) Memory in monkeys severely impaired by combined but not by separate removal of amygdala and hippocampus. Nature 273:297-298.

Morrison JH, Hof PR (1997) Life and death of neurons in the aging brain. Science 278:412-419.

Moss MB, Rosene DL, Peters A (1988) Effects of aging on visual recognition memory in the rhesus monkey. Neurobiol Aging 9:495-502.

Peters A, Kaiserman-Abramof IR (1969) The small pyramidal neuron of the rat cerebral cortex. The synapses upon dendritic spines. Z Zellforsch Mikrosk Anat 100:487-506.

Peters A, Rosene DL, Moss MB, Kemper TL, Abraham CR, Tigges J, Albert MS (1996) Neurobiological bases of age-related cognitive decline in the rhesus monkey. J Neuropathol Exp Neurol 55:861-874.

Peters A, Jones EG, Morrison JH (1999) Cerebral cortex: neurodegenerative and age-related changes in structure and function of cerebral cortex. New York: Springer.

Presty SK, Bachevalier J, Walker LC, Struble RG, Price DL, Mishkin M, Cork
LC (1987) Age differences in recognition memory of the rhesus monkey (Macaca mulatta). Neurobiol Aging 8:435-440.

Prokop A, Landgraf M, Rushton E, Broadie K, Bate M (1996) Presynaptic development at the Drosophila neuromuscular junction: assembly and localization of presynaptic active zones. Neuron 17:617-626.

Rapp PR (1995) Emotion, memory and behavior: studies on human and nonhuman primates. Tokyo: Japan Scientific Societies.

Rapp PR, Amaral DG (1991) Recognition memory deficits in a subpopulation of aged monkeys resemble the effects of medial temporal lobe damage. Neurobiol Aging 12:481-486.

Rapp PR, Morrison JH, Roberts JA (2003) Cyclic estrogen replacement improves cognitive function in aged ovariectomized rhesus monkeys. J Neurosci 23:5708-5714.

Shamy JL, Buonocore MH, Makaron LM, Amaral DG, Barnes CA, Rapp PR (2006) Hippocampal volume is preserved and fails to predict recognition memory impairment in aged rhesus monkeys (Macaca mulatta). Neurobiol Aging 27:1405-1415.

Small JD (1968) Measurement of section thickness. In: Proceedings of the 4th European Congress on Electron Microscopy, Rome, pp 609-610.

Small SA, Chawla MK, Buonocore M, Rapp PR, Barnes CA (2004) Imaging correlates of brain function in monkeys and rats isolates a hippocampal subregion differentially vulnerable to aging. Proc Natl Acad Sci U S A 101:7181-7186.

Squire LR, Zola-Morgan S (1991) The medial temporal lobe memory system. Science 253:1380-1386.

Tigges J, Gordon TP, McClure HM, Hall EC, Peters A (1988) Survival rate and life span of rhesus monkeys at the Yerkes regional primate research center. Am J Primatol 15:263-273.

Tigges J, Herndon JG, Rosene DL (1995) Mild age-related changes in the dentate gyrus of adult rhesus monkeys. Acta Anat (Basel) 153:39-48.

Tigges J, Herndon JG, Rosene DL (1996) Preservation into old age of synaptic number and size in the supragranular layer of the dentate gyrus in rhesus monkeys. Acta Anat (Basel) 157:63-72.

Toni N, Buchs PA, Nikonenko I, Bron CR, Muller D (1999) LTP promotes formation of multiple spine synapses between a single axon terminal and a dendrite. Nature 402:421-425.

Toni N, Buchs PA, Nikonenko I, Povilaitite P, Parisi L, Muller D (2001) Remodeling of synaptic membranes after induction of long-term potentiation. J Neurosci 21:6245-6251.

Walker ML, Herndon JG (2008) Menopause in nonhuman primates? Biol Reprod 79:398-406.

Witter MP, Van Hoesen GW, Amaral DG (1989) Topographical organization of the entorhinal projection to the dentate gyrus of the monkey. J Neurosci 9:216-228.

Woolley CS, Wenzel HJ, Schwartzkroin PA (1996) Estradiol increases the frequency of multiple synapse boutons in the hippocampal CA1 region of the adult female rat. J Comp Neurol 373:108-117.

Yang G, Pan F, Gan WB (2009) Stably maintained dendritic spines are associated with lifelong memories. Nature 462:920-924.

Yankova M, Hart SA, Woolley CS (2001) Estrogen increases synaptic connectivity between single presynaptic inputs and multiple postsynaptic CA1 pyramidal cells: a serial electron-microscopic study. Proc Natl Acad Sci U S A 98:3525-3530.

Yassa MA, Muftuler LT, Stark CE (2010) Ultrahigh-resolution microstructural diffusion tensor imaging reveals perforant path degradation in aged humans in vivo. Proc Natl Acad Sci U S A 107:12687-12691. 